\title{
AVALIAÇÃO DO DESENVOLVIMENTO DE COMPETÊNCIAS A PARTIR DA ATUAÇÃO NA EXTENSÃO UNIVERSITÁRIA: UMA EXPERIÊNCIA DE ESTUDANTES DAS ÁREAS DE TECNOLOGIA
}

\author{
EVALUATION OF SKILLS DEVELOPMENT FROM UNIVERSITY EXTENSION ACTIONS: AN \\ EXPERIENCE OF STUDENTS IN TECHNOLOGICAL AREAS
}

Wagner Ragi Curi Filho스, Paganini Barcellos de Oliveira², Bruno Souza Ramos ${ }^{3}$, Isabella Maria Candido ${ }^{4}$,Vinicius Fernandes Silva ${ }^{5}$

DOI: 10.37702/REE2236-0158.v40p266-278.2021

\section{RESUMO}

Este trabalho propõe uma metodologia para avaliação do desenvolvimento de competências em estudantes de cursos de áreas tecnológicas, a partir de experiências vinculadas a um conjunto de atividades pertencentes a dois projetos de extensão, executados em paralelo, em uma cidade do interior de Minas Gerais. Esse modelo foi utilizado para avaliar competências de um grupo de estudantes de cursos das áreas de tecnologia. As ações de extensão desenvolvidas pelos estudantes eram voltadas para organização de vídeos e oferecimento de cursos em formato remoto para docentes de uma escola pública. Foram exploradas duas dimensões para avaliação das competências, a percepção individual, por meio do processo de autoavaliação, e a coletiva, resultante de um procedimento de avaliação $360^{\circ}$. Como resultado, verificou-se que o modelo proposto estava apto a analisar o desenvolvimento dos estudantes a partir da avaliação de oito agrupamentos de competências. Das competências avaliadas, em apenas duas não houve um aumento percentual médio das competências nos estudantes. Foi constatado também que a percepção individual das habilidades aprimoradas pelos estudantes tende a ser uma avaliação mais crítica do que a ótica coletiva. A partir dos resultados obtidos é possível concluir que as ações de extensão podem contribuir direta e positivamente para o desenvolvimento de competências necessárias para a formação de estudantes das áreas tecnológicas.

Palavras-chave: extensão universitária; competências; avaliação.

\begin{abstract}
This work proposes a methodology for assessing the skills development in students of technology courses based on experiences linked to a set of activities belonging to two extension projects, carried out in parallel, in a country town of Minas Gerais. This model was used to assess the skills of a group of students in the technology courses. The extension actions developed by the students consisted of producing videos and offering courses in remote format for teachers at a public school. Two dimensions were investigated for the assessment of skills, the individual perception, through the self-

\footnotetext{
${ }^{1}$ Professor Adjunto, doutor em Administração, Instituto de Ciências Exatas e Aplicadas da Universidade Federal de Ouro Preto - ICEA/UFOP - João Monlevade; wagner@ufop.edu.br

${ }^{2}$ Professor Adjunto, doutor em Engenharia de Produção, Instituto de Ciências Exatas e Aplicadas da Universidade Federal de Ouro Preto - ICEA/UFOP - João Monlevade; paganini@ufop.edu.br

${ }^{3}$ Bolsista de Extensão e aluno do curso de Engenharia da Computação da Universidade Federal de Ouro Preto - UFOP - João Monlevade; bruno.ramos1@aluno.ufop.edu.br

${ }^{4}$ Bolsista de Extensão e aluna do curso de Engenharia de Produção da Universidade Federal de Ouro Preto - UFOP - João Monlevade; isabella.candido@aluno.ufop.edu.br

5 Bolsista de Extensão e aluno de Engenharia de Produção da Universidade Federal de Ouro Preto - UFOP - João Monlevade; bruno.ramos1@aluno.ufop.edu.br
} 
assessment process, and the collective opinion, from a 360-degree feedback procedure. As a result, it was found that the proposed model was able to analyze student performance, based on the assessment of eigth skill groups. Among the skills assessed, only two did not show an average percentage increase in students' skills. It was also found that the individual perception of the skills improved by the students tends to be a more critical assessment than the collective view. Based on the results obtained, it is possible to conclude that the extension actions can directly and positively contribute to the increase of skills in the learning process of students in technological areas.

Keywords: university extension; skills; evaluation.

\section{INTRODUÇÃO}

O processo de formação dos profissionais das áreas tecnológicas está em amplo debate, especialmente no que diz respeito a aspectos que envolvem o desenvolvimento de competências e aproximação do ensino com maior possibilidade de prática (SÁ, 2019; FERREIRA et al., 2020).

Diante do debate da inserção da discussão da prática na formação dos profissionais das áreas tecnológicas, diversas possibilidades são debatidas. Uma delas está relacionada a se trazer à tona, em uma perspectiva mais concreta, a indissociabilidade do ensino, da pesquisa e da extensão. Desse modo, os processos de aprendizagem provenientes de experiências da extensão, da pesquisa e dos modos tradicionais de ensino proporcionam competências distintas e complementares (COELHO, 2014; CHAVES; POMPEU, 2018).

$\mathrm{O}$ debate envolvendo o desenvolvimento de competências é questão-chave nas novas Diretrizes Curriculares Nacionais (DCNs) para os cursos de Engenharia (MEC, 2019). É importante ressaltar que o termo competência pode adquirir significados variados, mas, de uma maneira geral, o conceito de competência remete à capacidade que um indivíduo (ou um grupo ou uma organização) possui em mobilizar habilidades e conhecimentos visando a solução de problemas (ZARIFIAN, 2005).

Considerando as ações de extensão como reais oportunidades de desenvolvimento de competências na formação de estudantes de cursos das áreas tecnológicas, este trabalho apresenta uma reflexão sobre como as competências de um grupo de estudantes desenvolveram-se ao longo da execução de um conjunto de ações de extensão. Avaliou-se as competências na formação do aluno (NAKAO et al., 2012; FRANÇA; MELLET, 2016; JUNGER; FACÓ, 2017; DAL-BIANCO et al., 2018), tendo como ponto principal a análise do desenvolvimento das competências exigidas nas novas DCNs.

Visando a contribuir para o debate teórico da avaliação do Ensino de Engenharia, este trabalho propôs uma metodologia de avaliação de competências baseada em uma breve revisão bibliográfica. Ademais, o trabalho pode gerar implicações práticas na medida em que o modelo foi utilizado por um grupo de estudantes que se autoavaliaram (nas dimensões propostas) acerca de suas competências. O processo de autoavaliação se deu ao longo da execução de ações de extensão voltadas para organização de vídeos e cursos em formato remoto para docentes de uma escola pública de uma cidade do interior de Minas Gerais. Participaram estudantes vinculados aos cursos de Engenharia de Produção, Engenharia Elétrica, Engenharia de Computação e Sistemas de Informação.

Embora se mencione, sobremaneira, a respeito da indissociabilidade do ensino, da extensão e da pesquisa, compreender o papel da extensão na formação dos discentes ainda é um desafio (SÁ, 2019). Entretanto, o fortalecimento do debate sobre a formação de competências nos estudantes das áreas tecnológicas traz novas nuances para o processo de ensino-aprendizagem, tais como aquelas relacionadas ao desenvolvimento de competências a partir da atuação em ações de extensão. Cabe salientar também que a obrigatoriedade do que tem sido chamado curricularização da extensão (DE OLIVEIRA; 
TOSTA; DE FREITAS, 2020) ajuda a fortalecer a necessidade de compreensão de como os processos de formação dos egressos, de uma forma geral, passa pelas competências desenvolvidas a partir da extensão universitária.

\section{REVISÃO TEÓRICA}

\section{O papel da extensão na formação do estudante de engenharia}

A extensão permite ao aluno entrar em contato com a comunidade externa à universidade, conhecendo melhor a realidade que lhe cerca, e também possibilita ao aluno a opção de articular seus conhecimentos teóricos com as realidades práticas. Além disso, as ações extensionistas permitem aos alunos desenvolverem/aperfeiçoarem um conjunto de competências pautadas em consonância com as DCNs de engenharias publicadas em 2019. Kölln et al. (2018, p. 21) sintetizam a contribuição das ações de extensão para o desenvolvimento de competências nos estudantes de engenharia nos seguintes aspectos:

a) visão abrangente do conhecimento, sobretudo os específicos da Engenharia;

b) formação humanista e cultural;

c) capacidade de tomar decisões com espírito crítico, permitindo-lhe apresentar soluções para os problemas teóricos e práticos;

d) qualidades de liderança, dinamismo e capacidade de trabalho em equipe;

e) capacidade de interferência positiva na realidade socioeconômica, científica e cultural do país, como agente transformador da sociedade;

f) capacidade de comunicação eficientemente nas formas escrita, oral e gráfica;

g) capacidade de compreender e aplicar a ética e a responsabilidade profissional;

h) capacidade de avaliar o impacto das atividades da engenharia no contexto social e ambiental; i) capacidade de assumir a postura de permanente busca de atualização profissional.

Ainda segundo Kölln et al. (2018), o desenvolvimento de tais habilidades decorre do contato direto com a comunidade, na qual o aluno irá lidar com situações novas e diversas, tendo que colocar em prática os aprendizados obtidos em sala de aula para solucionar os problemas reais. Ademais, cabe destacar a formação cidadã para a qual a extensão pode contribuir. Nesse sentido, Santos, Rocha e Passaglio (2016) afirmam que a participação na extensão universitária permite aos discentes identificarem novas alternativas de trabalho, via de regra, distintas daquelas tradicionais, focadas em grandes empresas.

\section{Competências na formação do estudante de engenharia}

Segundo Cotta, da Costa e de Mendonça (2015), competência se trata do conjunto de aptidões nos âmbitos pessoal, social e/ou metodológico que possibilita ao indivíduo a resolução de problemas nas mais variadas situações em que este pode estar envolvido, seja no contexto acadêmico, profissional, social ou pessoal. Essas habilidades permitem participação ativa na sociedade, uma vez que o estudante passa a saber utilizar melhor as informações, conhecimentos e sua capacidade técnica, assumindo atitudes específicas para situações distintas e alcançando resultados factíveis e úteis para a sociedade, seja para o ambiente seja para as pessoas (COTTA; DA COSTA; DE MENDONÇA, 2015).

Carvalho e Tonini (2017), interpretando Zarifian (2012), entendem que competência se traduz em duas ações que representam a autonomia que o ser humano tem em: tomar iniciativa e assumir responsabilidade. A primeira diz respeito ao uso de experiências e conhecimentos para lidar com situações imprevisíveis. Já a segunda trata da compreensão em relação aos efeitos desse uso.

Silva, Korzenowski e Dall'Agnol (2016) compilam noções de competência de alguns autores que as dividem em grupos, mas 
apresentam enfoques diferentes. Resnick (1997), por exemplo, classifica em competências básicas competências gerais ou transferíveis e competências específicas ou técnicas. Gílio (2000) adiciona em sua definição a educação básica e cognitiva no âmbito dos conhecimentos técnicos. Já Resende e Paula (2000) dividem as competências em atributos pessoais, comportamentais e de conhecimento.

Segundo o CNE/CES (MEC, 2019), um profissional formado em um curso de engenharia precisa adquirir ao longo de sua formação um conjunto de competências e habilidades que lhe permitam atuar adequadamente em suas atividades profissionais. Em síntese, a formação do engenheiro deve contribuir para que o profissional seja capaz de: colocar em prática conhecimentos da engenharia; conduzir experimentos; interpretar resultados; lidar com sistemas, produtos, processos e serviços; resolver problemas; desenvolver ferramentas e técnicas; supervisionar e avaliar criticamente operação e manutenção; comunicar-se de maneira eficiente; trabalhar em equipe multidisciplinar; aplicar ética e responsabilidade profissional; avaliar o impacto das atividades da engenharia no que diz respeito ao social e ao ambiental; avaliar viabilidade econômica de projetos; e sempre buscar atualização profissional.

De acordo com Cotta, da Costa e de Mendonça (2015), a formação a partir da compreensão e utilização dessas competências é de extrema valia, uma vez que aproxima o que é estudado às demandas que a sociedade exige do profissional, além de estimular habilidades psicossociais cognitivas e não-cognitivas, integrando saberes que se fazem necessários para resolução de problemas nos mais diversos cenários.

Ademais, Santos (2003) acrescenta que as competências se tornaram elementos importantes para as diretrizes curriculares, por permitirem nortear os objetivos de formação, desenvolvimento, avaliação e acompanhamento dos alunos. Nessa perspectiva, os cursos de graduação das mais distintas áreas vêm desenvolvendo estratégias de aprendizagem que visam a ampliar o desenvolvimento de competências nos estudantes. No campo da engenharia não é diferente, e as DCNs publicadas em 2019 deixam claro a preocupação do Conselho Nacional de Educação em fazer com que os engenheiros e engenheiras brasileiros e brasileiras desenvolvam competências variadas, sejam elas técnicas ou comportamentais (NAKAO et al., 2012).

Assim, ações de extensão universitária, além de contribuir para que as universidades exerçam um impacto social positivo na sociedade, podem se constituir como grandes oportunidades para o desenvolvimento de competências nos estudantes de engenharia.

\section{METODOLOGIA}

Com o objetivo de compreender como a participação em duas ações de extensão ajudaram no desenvolvimento de competências de um grupo de sete estudantes de áreas tecnológicas, esta pesquisa estruturou-se a partir de um conjunto de procedimentos metodológicos. Em um primeiro momento, foi realizada uma revisão de literatura, que incluiu o estudo dos conceitos e definições sobre competências que caracterizam as demandas para formação dos estudantes dos cursos de graduação em engenharia, orientadas pelas DCNs, e também a investigação do papel da extensão e sua contribuição na formação dos estudantes de nível superior.

Em um segundo momento, tendo como base os trabalhos de Nakao et al. (2012) e Gomes e Silva (2019), elaborou-se uma planilha contendo oito agrupamentos de 19 competências conforme apresentado no Quadro 1.

Após a identificação das competências a serem avaliadas, os estudantes (ainda nos dois primeiros meses de participação nas ações de extensão) se autoavaliaram, atribuindo uma nota de 1 a 7 para cada uma das 19 competências. Cabe ressaltar que o conceito de cada competência foi debatido em reuniões de formação (com participação dos docentes coordenadores das ações) que buscaram sanar 
dúvidas de compreensão do que cada competência significava.

O Quadro 2 (localizado nos Apêndices) apresenta com mais detalhes um instrumento que foi elaborado para ajudar os estudantes no preenchimento da planilha de autoavaliação.

Ao fim do primeiro ano de execução das ações de extensão, os estudantes realizaram uma nova autoavaliação, novamente atribuindo notas de 1 a 7 para cada competência avaliada. Fazendo a avaliação nesses dois momentos, esperava-se verificar se os estudantes se autoavaliaram de forma distinta (ou não) em cada competência.

Quadro 1 - Agrupamentos e competências

\begin{tabular}{|c|c|}
\hline Agrupamento & Competência \\
\hline \multirow[b]{2}{*}{ Avaliaçào } & Auto-imagem \\
\hline & Controle emocional \\
\hline \multirow[b]{2}{*}{ Regularidade } & Organizaçào \\
\hline & Planejamento \\
\hline \multirow[b]{3}{*}{ Comunicaçào } & Oral \\
\hline & Escrita \\
\hline & Gráfica \\
\hline \multirow[b]{2}{*}{ Ensino } & Integraçào \\
\hline & Didática \\
\hline \multirow[b]{4}{*}{ Regência } & Controle \\
\hline & Decisão \\
\hline & Liderança \\
\hline & Administração de conflitos \\
\hline Comutaçào & Disposiçào para mudanças \\
\hline \multirow[b]{3}{*}{ Afabilidade } & Protagonismo \\
\hline & Afetividade \\
\hline & Sociabilidade \\
\hline \multirow[b]{2}{*}{ Desempenho } & Detalhismo \\
\hline & Tempo de execuçào \\
\hline
\end{tabular}

Fonte: elaborado pelos autores a partir de Nakao et al. (2012) e Gomes e Silva (2019).

Em um terceiro momento, os estudantes avaliaram como eles enxergavam as competências dos colegas em uma espécie de avaliação $360^{\circ}$ (HENSEL et al., 2010). Salienta-se que, nesta etapa, dois professores também participaram. A avaliação realizada neste momento visava a identificar se existiam diferenças nas competências identificadas pela autoavaliação em relação às competências percebidas pelos outros estudantes. Assim, por exemplo, o estudante pode se considerar um bom administrador de conflitos, mas os demais participantes não perceberem essa competência.

Para realizar a avaliação $360^{\circ}$, cada um dos sete estudantes respondeu o que achava dos outros seis, atribuindo (no fim das ações) nota de 1 a 7 para cada participante, para cada competência. $\mathrm{O}$ instrumento de avaliação permitia também destacar, de forma discursiva, os pontos fortes do seu colega e os pontos a serem melhorados.

Para a realização da análise dos dados, as notas atribuídas no processo de avaliação das competências e autoavaliação dos participantes da pesquisa foram confrontadas e avaliadas de maneira conjunta. Nesse caso, foram calculados valores médios, a fim de encontrar um score para as competências do participante, ou seja, definir um valor médio que representaria todas as competências que o participante julgava ter no início e no fim do projeto. Esse procedimento permitiu avaliar a evolução do participante no decorrer da realização das ações extensionistas. Por fim, a métrica dos scores foi estendida para a avaliação $360^{\circ}$ e comparada com os scores da autoavaliação final. Esses procedimentos foram suficientes para o cálculo dos índices de crescimento médio das competências dos participantes, que, por sua vez, oferecem uma visão holística do impacto da extensão no desenvolvimento de competências nos estudantes.

\section{RESULTADOS E DISCUSSÃO}

\section{Descrição das ações de extensão}

Este trabalho foi elaborado a partir da atuação de estudantes em duas ações de extensão realizadas concomitantemente por alunos de engenharia da Universidade Federal de Ouro Preto 6 . 
A ação Gestão para todos consistia em duas atividades:

1) Realizar entrevistas com pessoas da comunidade sobre como elas enxergavam a relação da universidade com a comunidade local - os estudantes deviam organizar roteiros, procurar os entrevistados, realizar as entrevistas, editar os vídeos e postar os vídeos na plataforma YouTube.

2) Elaborar vídeos curtos animados dando dicas de gestão e explicações de conteúdos de engenharia que possam ajudar no cotidiano das pessoas, tais como qualidade e computação na nuvem - os estudantes tiveram que definir temas, roteiros, aprender a utilizar o software, gravar e editar os vídeos e postá-los na plataforma YouTube.

Já a Ação nas escolas também foi composta por duas atividades:

1) Realização de entrevistas com profissionais e alunos, com debate de temas variados relacionados à educação, tais como jogos digitais, Enem digital, redes sociais e o impacto da pandemia no processo de aprendizagem - os estudantes deviam organizar roteiros, procurar os entrevistados, realizar as entrevistas, editar os vídeos e postá-los na plataforma YouTube.

2) Realizar um curso de Edição de Planilhas Eletrônicas (realizado de forma remota) para os docentes de uma escola pública da cidade João Monlevade - MG. Foram oferecidas uma turma de nível básico e duas turmas de nível intermediário. Cada turma teve seis aulas de duas horas cada - os estudantes foram responsáveis por preparar os planos de aula, elaborar e lecionar as aulas propriamente ditas, preparar exercícios e sanar dúvidas, além de manter a comunicação com os professores-alunos em grupos de WhatsApp.

\section{Avaliação das competências}

Apresentadas as ações de extensão, podese voltar ao debate acerca de como as competências foram avaliadas. A Tabela 1 apresenta a diferença de nota atribuída no processo de autoavaliação dos participantes no final das ações de extensão e as notas de início, para cada uma das 19 competências. Por exemplo, o aluno Número 3 atribuiu, no início de sua participação, uma dada nota $X$ para a competência Decisão e uma nota $\mathrm{X}+3$, para a mesma competência após um ano de participação; portanto, seu score será de 3 .

Já a Tabela 2 apresenta as médias aritméticas das respostas dos estudantes nos dois momentos de autoavaliação em relação a todas as competências avaliadas. Tem-se, por exemplo, a média do aluno Número 3, em que a média de suas respostas no início de sua participação foi 4,26 e, após um ano atuando nas ações de extensão, foi de 4,58 (a escala foi de 0 a 7).

Tabela 1 - Autoavaliação dos estudantes ( $2^{\circ}$ momento de avaliação $-1^{\circ}$ momento de avaliação)

\begin{tabular}{|l|c|c|c|c|c|c|c|}
\hline \multirow{2}{*}{\multicolumn{1}{c|}{ Competências }} & \multicolumn{6}{|c|}{ Alunos } \\
\cline { 2 - 8 } & $\mathbf{1}$ & $\mathbf{2}$ & $\mathbf{3}$ & $\mathbf{4}$ & $\mathbf{5}$ & $\mathbf{6}$ & $\mathbf{7}$ \\
\hline Auto-imagem & 0 & 0 & 0 & 0 & 0 & 0 & 0 \\
\hline Controle emocional & -2 & 2 & -2 & -2 & -2 & -2 & -2 \\
\hline Organizaçào & 2 & -2 & 2 & 2 & 2 & 2 & 2 \\
\hline Planejamento & 1 & -1 & 1 & 1 & 1 & 1 & 1 \\
\hline Oral & 0 & 0 & 0 & 0 & 0 & 0 & 0 \\
\hline Escrita & 0 & 0 & 0 & 0 & 0 & 0 & 0 \\
\hline Gráfica & 0 & 0 & 0 & 0 & 0 & 0 & 0 \\
\hline Integraçào & 1 & -1 & 1 & 1 & 1 & 1 & 1 \\
\hline Didática & 1 & -1 & 1 & 1 & 1 & 1 & 1 \\
\hline Controle & -1 & 1 & -1 & -1 & 1 & -1 & -1 \\
\hline Decisào & 3 & -3 & 3 & 3 & 3 & 3 & 3 \\
\hline Liderança & 1 & -1 & 1 & 1 & 1 & 1 & 1 \\
\hline Administraçào de conflitos & 2 & -2 & 2 & 2 & 2 & 2 & 2 \\
\hline Disposiçào para mudanças & -1 & 1 & -1 & -1 & -1 & -1 & -1 \\
\hline Protagonismo & 1 & -1 & 1 & 1 & 1 & 1 & 1 \\
\hline Afetividade & 0 & 0 & 0 & 0 & 0 & 0 & 0 \\
\hline Sociabilidade & 2 & -2 & 2 & 2 & 2 & 2 & 2 \\
\hline Detalhismo & 1 & -1 & 1 & 1 & 1 & 1 & 1 \\
\hline Tempo de Execução & 0 & 0 & 0 & 0 & 0 & 0 & 0 \\
\hline
\end{tabular}

Fonte: elaborado pelos autores. 
A Tabela 3 indica qual foi o percentual de evolução dos alunos em relação aos dois momentos, subtraindo-se o score do $2^{\circ}$ momento pelo score do $1^{\mathrm{o}}$ momento. A autoavaliação do aluno de Número 1, por exemplo, gerou média de 4,58 $(66,41 \%)$ no primeiro momento de avaliação e 5,16 no segundo momento. Isso significa que a variação do score do aluno de Número 1 foi de 0,58 ou $8,27 \%$.

O aluno Número 5 foi aquele que apresentou maior ampliação de competências (por meio do processo de autoavaliação). Por outro lado, o aluno Número 6 praticamente não enxerga que suas competências melhoraram a partir de sua participação nas ações de extensão. Ademais, pode-se observar que o percentual médio de evolução das competências dos alunos participantes foi de $5,37 \%$.

Tabela 2 - Média dos Scores de autoavaliação dos alunos nos $1^{\circ}$ e $2^{\circ}$ momentos

\begin{tabular}{|c|c|c|}
\hline \multicolumn{3}{|c|}{ Dados Coletados } \\
\hline Aluno & $\begin{array}{c}\text { Score da } \\
\text { Autoavaliação } \\
\mathbf{1}^{\mathbf{0}} \text { momento }\end{array}$ & $\begin{array}{c}\text { Score da } \\
\text { Autoavaliação } \\
\mathbf{2}^{\mathbf{0}} \text { momento }\end{array}$ \\
\hline $\mathbf{1}$ & 4,58 & 5,16 \\
\hline $\mathbf{2}$ & 4,58 & 4,89 \\
\hline $\mathbf{3}$ & 4,26 & 4,58 \\
\hline $\mathbf{4}$ & 5,00 & 5,11 \\
\hline $\mathbf{5}$ & 4,05 & 5,21 \\
\hline $\mathbf{6}$ & 4,68 & 4,74 \\
\hline $\mathbf{7}$ & 5,05 & 5,16 \\
\hline
\end{tabular}

Fonte: elaborado pelos autores.

Tabela 3 - Scores de autoavaliação dos alunos nos $1^{\circ}$ e $2^{\circ}$ momentos e percentual médio de evolução

\begin{tabular}{|c|c|c|c|}
\hline \multicolumn{4}{|c|}{ Dados Coletados (\%) } \\
\hline Aluno & $\begin{array}{c}\text { Score da } \\
\text { Autoavaliação } \\
\mathbf{1}^{\mathbf{0}} \text { momento }\end{array}$ & $\begin{array}{c}\text { Score da } \\
\text { Autoavaliação } \\
\mathbf{2}^{\mathbf{0}} \text { momento }\end{array}$ & Variação \\
\hline $\mathbf{1}$ & 65,41 & 73,68 & 8,27 \\
\hline $\mathbf{2}$ & 65,41 & 69,92 & 4,51 \\
\hline $\mathbf{3}$ & 60,9 & 65,41 & 4,51 \\
\hline $\mathbf{4}$ & 71,43 & 72,93 & 1,50 \\
\hline $\mathbf{5}$ & 57,89 & 74,44 & 16,55 \\
\hline $\mathbf{6}$ & 66,92 & 67,67 & 0,75 \\
\hline $\mathbf{7}$ & 72,18 & 73,68 & 1,50 \\
\hline \multicolumn{4}{|c|}{ Variação média } \\
\hline
\end{tabular}

Fonte: elaborado pelos autores.
A Tabela 4 apresenta os scores de autoavaliação e avaliação $360^{\circ}$ para os sete alunos. A avaliação $360^{\circ}$, em formato de feedback, consistiu em uma análise de todos os participantes do projeto, a partir da qual estes puderam avaliar uns aos outros, de acordo com as competências, e também se autoavaliar de uma maneira construtiva.

Para a avaliação $360^{\circ}$, levou-se em consideração:

a) uma avaliação de 0 a 7 , de acordo com as competências;

b) citação de pontos fortes do avaliado, de acordo com as competências;

c) proposta de melhorias, de acordo com as competências.

A Tabela 4 permite que se visualize as médias obtidas pelos estudantes a partir das notas atribuídas pelos seus colegas (e docentes), além da média das notas da autoavaliação realizada no $2^{\circ}$ momento de autoavaliação, ocorrido após um ano das ações de extensão.

Tabela 4 - Média dos Scores de Auto Avaliação e Avaliação $360^{\circ}$ (escala de 0-7)

\begin{tabular}{|c|c|c|}
\hline Aluno & $\begin{array}{c}\text { Score da } \\
\text { Autoavaliação }\end{array}$ & $\begin{array}{c}\text { Score da } \\
\text { Avaliação } \mathbf{3 6 0}^{\circ}\end{array}$ \\
\hline $\mathbf{1}$ & 5,16 & 6,53 \\
\hline $\mathbf{2}$ & 4,89 & 5,91 \\
\hline $\mathbf{3}$ & 4,58 & 5,13 \\
\hline $\mathbf{4}$ & 5,11 & 5,44 \\
\hline $\mathbf{5}$ & 5,21 & 6,22 \\
\hline $\mathbf{6}$ & 4,74 & 5,60 \\
\hline $\mathbf{7}$ & 5,16 & 6,07 \\
\hline
\end{tabular}

Fonte: elaborado pelos autores.

Ao avaliar a Tabela 4, percebe-se que a avaliação $360^{\circ}$ gerou um score que indica que a avaliação dos outros integrantes do grupo sobre cada aluno foi melhor do que a avaliação de cada um sobre si mesmo, para todos os estudantes.

Salienta-se que a avaliação $360^{\circ}$ também permitiu aos estudantes destacarem, qualitativamente, os pontos fortes e fracos dos colegas. Portanto, ocorreram relatos que demonstram o comprometimento dos alunos e a sua evolução ao longo da ação da extensão. Trata-se de relatos que ressaltam os pontos fortes dos colegas. Seguem alguns exemplos: 
"No curso de planilhas teve um bom desempenho em relação à comunicação, organização e calma para ensinar. Se mostrou flexível e receptiva, assim como transmitiu tranquilidade para os demais colegas e alunos do curso." (relato de um dos alunos no processo de avaliação $360^{\circ}$, destacando aspectos positivos de um colega)

"Excelente comunicação, prestativo e sempre disposto a ajudar, executa bem suas atividades, realmente um dos destaques da equipe." (relato de um dos alunos no processo de avaliação $360^{\circ}$, destacando aspectos positivos de um colega)

Há também relatos que demonstram que os alunos ainda precisam aprimorar algumas de suas competências. Seguem exemplos de relatos dessa natureza:

"Precisa melhorar nos quesitos de organização, cumprimento de prazos $e$ proatividade. Me pareceu um pouco tímida em alguns momentos." (relato de um dos alunos no processo de avaliação $360^{\circ}$ destacando aspectos de um colega que precisa ser melhorado)

"Precisa desenvolver mais suas habilidades de comunicação, melhorar a sua apresentação de ideias e redação científica." (relato de um dos alunos no processo de avaliação $360^{\circ}$ destacando aspectos de um colega que precisa ser melhorado)

Em suma, os relatos qualitativos da avaliação $360^{\circ}$ foram oportunidades através das quais estudantes puderam apresentar argumentos sobre como cada estudante era percebido pelo outro, constituindo-se em um exercício reflexivo que, por si só, também contribui para o desenvolvimento de competências.

De maneira similar à Tabela 3, a Tabela 5 indica a média percentual dos scores dos alunos, obtidos no $2^{\circ}$ momento de autoavaliação, e a média dos scores dos estudantes, obtidos a partir da avaliação realizada pelos colegas e professores. $\mathrm{Na}$ coluna "Divergência", pode ser observada a diferença entre essas duas avaliações. Percebese, por exemplo, que o aluno de Número 1 obteve scores de $73,68 \%$ na autoavaliação e 93,33\% na avaliação $360^{\circ}$; ou seja, há uma divergência de $19,64 \%$ no sentido de que os colegas e professores o avaliam melhor do que ele a si próprio. $\mathrm{Na}$ média, a avaliação $360^{\circ}$ gerou scores $12,38 \%$ maior do que aqueles obtidos no $2^{\circ}$ momento de autoavaliação.

A Tabela 6 apresenta os scores dos agrupamentos de competências apresentados na Metodologia (Quadro 1) nos $1^{\circ}$ e $2^{\circ}$ momentos de autoavaliação, além do percentual de mudança nos dois momentos. Para cada agrupamento, foi calculada a média das notas de cada competência definidas como parte daquele agrupamento.

Pode-se observar que os scores de dois agrupamentos diminuíram no $2^{\circ}$ momento, quando comparados ao $1^{\circ}$ momento. Entretanto, esse decremento não significa diretamente que a competência tenha diminuído. É possível que os alunos tenham sido mais críticos consigo no $2^{\circ}$ momento de avaliação; talvez influenciados pelo próprio debate realizado durante a ação de extensão. Esse resultado parece suscitar novos debates sobre a formação de competências.

Tabela 5 - Média percentual de evolução dos alunos considerando a divergência entre scores de Auto Avaliação e Avaliação $360^{\circ}$

\begin{tabular}{|c|c|c|c|}
\hline Aluno & \begin{tabular}{|c|} 
Score da \\
Autoavaliação \\
$(\%)$
\end{tabular} & $\begin{array}{c}\text { Score da } \\
\text { Avaliação } 360^{\circ} \\
(\%)\end{array}$ & $\begin{array}{c}\text { Divergência } \\
\text { (\%) }\end{array}$ \\
\hline 1 & 73,68 & 93,33 & 19,64 \\
\hline 2 & 69,92 & 84,44 & 14,52 \\
\hline 3 & 65,41 & 73,33 & 7,92 \\
\hline 4 & 72,93 & 77,77 & 4,84 \\
\hline 5 & 74,44 & 88,89 & 14,45 \\
\hline 6 & 67,67 & 80,00 & 12,33 \\
\hline 7 & 73,68 & 86,67 & 12,99 \\
\hline \multicolumn{3}{|c|}{ Divergência média } & 12,38 \\
\hline
\end{tabular}

Fonte: elaborada pelos autores. 
Tabela 6 - Scores dos agrupamentos nos $1^{\circ}$ e $2^{\circ}$ momentos e percentual médio de mudança

\begin{tabular}{|l|c|c|c|c|c|}
\hline \multirow{2}{*}{ Agrupamentos } & \multicolumn{2}{|c|}{$\mathbf{1}^{\circ}$ Momento } & \multicolumn{2}{|c|}{$\mathbf{2}^{\circ}$ Momento } & \multirow{2}{*}{ Variação } \\
\cline { 2 - 5 } & Média & Perc. & Média & Perc. & \\
\hline Avaliaçào & 5,85 & $83,57 \%$ & 5,07 & $72,42 \%$ & $-11,15 \%$ \\
\hline Regularidade & 4,78 & $68,28 \%$ & 5,28 & $75,42 \%$ & $7,14 \%$ \\
\hline Comunicação & 4,90 & $70,00 \%$ & 4,90 & $70,00 \%$ & $0,00 \%$ \\
\hline Ensino & 4,07 & $58,14 \%$ & 4,50 & $64,28 \%$ & $6,14 \%$ \\
\hline Regência & 4,39 & $62,71 \%$ & 4,96 & $70,85 \%$ & $8,14 \%$ \\
\hline Comutaçào & 5,14 & $73,42 \%$ & 5,71 & $81,57 \%$ & $8,15 \%$ \\
\hline Afabilidade & 4,19 & $59,85 \%$ & 5,00 & $71,42 \%$ & $11,57 \%$ \\
\hline Desempenho & 4,92 & $70,00 \%$ & 4,78 & $68,28 \%$ & $-1,72 \%$ \\
\hline \multicolumn{5}{|c|}{ Variação média } \\
\hline
\end{tabular}

Fonte: elaborado pelos autores.

Na média, no entanto, houve um aumento percentual médio de 3,53\%. Tal aumento sugere que as competências foram aprimoradas durante o projeto e que as ações de extensão podem contribuir direta e positivamente no desenvolvimento de competências em estudos das áreas tecnológicas.

\section{CONCLUSÕES}

Este artigo apresentou uma proposta de como avaliar as competências de estudantes desenvolvidas a partir da atuação em ações de extensão. Para tal, o artigo propôs avaliar o aumento/diminuição no nível de 19 competências de um grupo de sete estudantes de engenharia e sistemas de informação.

As 19 competências foram agrupadas em oito tipos: Avaliação, Regularidade, Comunicação, Ensino, Regência, Comutação, Afabilidade e Desempenho. A definição dos agrupamentos e das competências que foram avaliadas se deu a partir do estudo da literatura, especialmente dos trabalhos de Nakao et al. (2012) e Gomes e Silva (2019).

No início da execução das ações de extensão, cada um dos setes estudantes se autoavaliou para cada uma das 19 competências e novamente o fez, ao final de um ano de participação nas ações de extensão. Assim, foi possível avaliar como cada estudante enxergou seu crescimento (ou não) em relação àquela competência e grupo de competências. Embora seis dos oito grupos de competências tenham apresentado saldo positivo (notas ao final maiores que notas no início), dois grupos de competências - Avaliação e Desempenho apresentaram saldos negativos. Tais resultados sugerem que os estudantes foram mais rigorosos consigo no processo de autoavaliação ocorrido ao final de um ano das ações do que naquele realizado no início das ações.

Além dos resultados gerados pela autoavaliação, a proposta deste trabalho contempla uma comparação entre scores atribuídos pela autoavaliação e scores atribuídos por uma avaliação $360^{\circ}$. Portanto, cada estudante foi avaliado pelos pares e pelos docentes em cada uma das 19 competências (ao final do projeto). Tendo em vista que as médias das notas da avaliação $360^{\circ}$ foram sempre maiores do que as médias das notas atribuídas pela autoavaliação, é possível considerar que os estudantes são mais críticos consigo do que em relação a seus colegas.

Em meio ao debate sobre como os variados cursos de graduação contribuem para o desenvolvimento de competências nos estudantes, vários aspectos são suscitados, entre eles: como podemos avaliar o desenvolvimento de competências e como as ações de extensão podem contribuir nessa formação. Nesse sentido, este trabalho faz um esforço para contribuir com a temática, apresentando uma proposta de avaliação das competências que complementa outras alternativas e modelos já existentes. Para além da proposta de avaliação das competências, cabe destacar que este artigo foi elaborado também com a intenção de verificar e/ou ratificar a importância das ações de extensão no processo de formação dos estudantes de cursos de áreas tecnológicas.

Embora a proposta apresentada tenha ênfase no desenvolvimento de competências a partir da atuação em ações de extensão, é possível utilizá-la em outros contextos de aprendizagem, como uma disciplina, um projeto de iniciação científica entre outros.

Em relação a futuras pesquisas, uma primeira possibilidade é realizar estudos longitudinais monitorando outros estudantes que participem de outras ações de extensão ou de outros contextos de aprendizagem. Também será importante a realização de estudos identificando quais características de cada ação 
de extensão estão relacionadas a cada competência(s) ou grupo de competências avaliadas.

\section{REFERÊNCIAS}

CARVALHO, L.A.; TONINI, A. M. Uma análise comparativa entre as competências requeridas na atuação profissional do engenheiro contemporâneo e aquelas previstas nas diretrizes curriculares nacionais dos cursos de Engenharia. Gest. Prod., São Carlos, v. 24, n. 4, p. 829-841, 2017.

CHAVES, V. T.; POMPEU, L. P. Reflexões sobre a construção de outro paradigma na engenharia: potencialidades e limitações das tecnologias sociais e da extensão universitária.

Revista Tecnologia e Sociedade, v. 14, n. 32, p. 60-77, 2018.

COELHO, G. C. O papel pedagógico da extensão universitária. Revista Em Extensão, v. 13, n. 2, p. 11-24, 2014.

COTTA, R. M. M.; DA COSTA, G. D.; DE MENDONÇA, E. T. Portfólios críticoreflexivos: uma proposta pedagógica centrada nas competências cognitivas e metacognitivas. Interface, Botucatu, v. 19, n. 54, p. 573-588, jul./set. 2015.

DAL-BIANCO, D. P. et al. Implementação e análise de estratégias para o desenvolvimento de competências em um grupo de estudantes de Engenharia Química a partir de metodologias ativas. Revista de Ensino de Engenharia, v. 37, n. 2, 2018.

DE OLIVEIRA, C. V. N. C.; TOSTA, M. C. R.; DE FREITAS, R. R. Curricularização da extensão universitária: uma análise bibliométrica. Brazilian Journal of Production Engineering-BJPE, p. 114-127, 2020.

FERREIRA, P. J. G. et al. Indústria 4.0: Modelo de ensino para a formação de Engenheiros de Produção. Revista de Ensino de Engenharia, v. 38, n. 3, 2020.

FRANÇA, C.; MELLET, D. Soft Skills Required! Uma Análise da Demanda por Competências
Não-Técnicas de Profissionais para a Indústria de Software e Serviços. Anais... IX Fórum de Educação em Engenharia de Software (FEES 2016), p. 101-112, 2016.

GÍLIO, I. Trabalho e educação: formação profissional e mercado de trabalho. São Paulo: Nobel, 2000.

GOMES, F. S. C.; SILVA, A. S. V. A extensão universitária e a promoção de competências na formação do aluno de engenharia. Anais... XLVII Congresso Brasileiro de Educação em Engenharia, Fortaleza. 2019.

HENSEL, R. et al. 360 degree feedback: how many raters are needed for reliable ratings on the capacity to develop competences, with personal qualities as developmental goals? The International Journal of Human Resource Management, v. 21, n. 15, p. 2813-2830, 2010.

JUNGER, A. P.; FACÓ, J. F. B. Ensino em Engenharia de Produção com base no desenvolvimento de habilidades e competências. Research, Society and Development, v. 6, n. 3, p. 261-290, 2017.

KÖLLN, E. B. et al. Metodologia Aplicada ao Canteiro Escola: a experiência de um ano de projeto de extensão no Curso de Engenharia Civil na PUC Minas-São Gabriel. Conecte-se! Revista Interdisciplinar de Extensão, v. 2, n. 3, p. 17-30, 2018.

MEC. Ministério da Educação. Conselho Nacional de Educação/Câmara de Educação Superior. Resolução $\mathbf{n}^{0}$ 2, de 24 de abril de 2019. Institui as Diretrizes Curriculares Nacionais do Curso de Graduação em Engenharia. Disponível em: < https://www.in.gov.br/web/dou/$/$ resolu\%C3\%87\%C3\%83o-n\%C2\%BA-2-de24-de-abril-de-2019-85344528>. Acesso em: 07 dez. 2020.

NAKAO, O. S. et al. Mapeamento de competências dos formandos da Escola Politécnica da USP. Revista de Ensino de Engenharia, v. 31, n. 1, p. 31-39, 2012.

RESENDE, P.; PAULA, G. Inovações modernizantes e novos requisitos da formação 
profissional: um estudo de caso na indústria automobilística Brasileira. Anais... XXIV ANPAD, Florianópolis, 2000.

RESNICK, L. Students performance portfolios, in psychology and educational practice. Ed. Walbergandhaertel, McCutchan, p. 158-175, 1997.

SÁ, M. G. Em busca do impacto perdido? Experiências significativas com sentido local em pesquisa, ensino e extensão. Farol-Revista de Estudos Organizacionais e Sociedade, v. 6, n. 15, p. 364-398, 2019.

SANTOS, F. C. A. Potencialidades de mudanças na graduação em Engenharia de Produção geradas pelas diretrizes curriculares. Produção (São Paulo), São Paulo, v. 12, n. 2, p. 26-39, 2003.
SANTOS, J. H; ROCHA, B. F. ; PASSAGLIO, K. T. Extensão universitária e formação no ensino superior. Revista Brasileira de Extensão Universitária, v. 7, n. 1, p. 23-28, 2016.

SILVA, G. d. C.; KORZENOWSKI A. L.; DALL'AGNOL, M. Engenharia de Produção no Norte do Brasil: As competências de ensino na visão dos coordenadores de curso. Espacios. v. 37, n. 12, p. E-2, 2016.

ZARIFIAN, P. Produire de la valeur, mais quelle valeur? In: BERCOT, R. CONICK, F. (Ed.) L'Univers des services. Paris: L'Harmattan, 2005.

ZARIFIAN, P. Objetivo competência: por uma nova lógica. São Paulo: Atlas, 2012.

\section{APÊNDICES}

Quadro 2 - Planilha para o mapeamento das competências

\begin{tabular}{|c|c|c|c|c|c|}
\hline $\begin{array}{c}\text { Grupo de } \\
\text { competências }\end{array}$ & \begin{tabular}{|c|}
$\begin{array}{c}\text { Desdobramento dos } \\
\text { grupos }\end{array}$ \\
\end{tabular} & $\begin{array}{l}\text { Base para } \\
\text { caracterização das } \\
\text { competências }\end{array}$ & $\begin{array}{l}\text { Categorização } \\
\text { segundo as DCNEs } \\
\text { (MEC, 2019) }\end{array}$ & Pergunta chave & $\begin{array}{c}\text { Atividade Relacionada com } \\
\text { o desenvolvimento }\end{array}$ \\
\hline \multirow[b]{2}{*}{ Avaliação } & Auto-imagem & Nakao et al. (2012) & Auto-imagem & Você consegue se auto-avaliar? & Reuniòes \\
\hline & Controle emocional & Nakao et al. (2012) & Controle-emocional & $\begin{array}{l}\text { Mesmo diante da uma pandemia, você } \\
\text { conseguiu manter as atividades do } \\
\text { projeto da forma como pretendia? }\end{array}$ & Todas as atividades \\
\hline \multirow{2}{*}{ Regularidade } & Organizaçào & Nakao et al. (2012) & Organizaçào & $\begin{array}{l}\text { Você se manteve organizado com } \\
\text { relação às tarefas do projeto? }\end{array}$ & Todas as atividades \\
\hline & Planejamento & Nakao et al. (2012) & Planejamento & $\begin{array}{l}\text { Conseguiu definir estratégias para } \\
\text { alcançar o objetivo do projeto? }\end{array}$ & Todas as atividades \\
\hline \multirow{3}{*}{ Comunicaçâo } & Oral & Gomes e Silva (2019) & Comunicaçào & Consigo falar bem em público? & $\begin{array}{l}\text { Reuniòes / Aulas / } \\
\text { Entrevistas }\end{array}$ \\
\hline & Escrita & Gomes e Silva (2019) & Comunicaçào & $\begin{array}{l}\text { Escrevo de forma conexa e com poucos } \\
\text { erros? }\end{array}$ & $\begin{array}{l}\text { Planejamento da aula / Aulas } \\
\text { / Atividades }\end{array}$ \\
\hline & Gráfica & Gomes e Silva (2019) & Comunicação & $\begin{array}{l}\text { Consigo entender e usar tipos diferentes } \\
\text { de gráficos? }\end{array}$ & Planejamento da aula / Aulas \\
\hline \multirow{2}{*}{ Ensino } & Integraçào & Nakao et al. (2012) & Integraçào & $\begin{array}{l}\text { Consigo integrar tecnologia com o } \\
\text { ensino? }\end{array}$ & Planejamento da aula \\
\hline & Didática & Nakao et al. (2012) & $\begin{array}{l}\text { Comunicaçào / } \\
\text { Integraçâa }\end{array}$ & Possuo alguma técnica de ensino? & Planejamento da aula / Aulas \\
\hline \multirow{4}{*}{ Regência } & Controle & Nakao et al. (2012) & Controle & Consigo gerenciar atividades? & Aulas / Trabalho em equipe \\
\hline & Decisào & Nakao et al. (2012) & Decisào & Tenho dificuldade para tomar decisões? & Todas as atividades \\
\hline & Liderança & Nakao et al. (2012) & Liderança & $\begin{array}{l}\text { Sou capaz de conduzir de pessoas até } \\
\text { algum objetivo? }\end{array}$ & Aulas / Trabalho em equipe \\
\hline & $\begin{array}{l}\text { Administração de } \\
\text { conflitos }\end{array}$ & Nakao et al. (2012) & $\begin{array}{l}\text { Administraçào de } \\
\text { conflitos }\end{array}$ & Consigo gerenciar conflitos? & Aulas / Trabalho em equipe \\
\hline Comutaçào & \begin{tabular}{|l|} 
Disposiçào para \\
mudanças
\end{tabular} & Nakao et al. (2012) & $\begin{array}{l}\text { Disposiçào para } \\
\text { mudanças }\end{array}$ & $\begin{array}{l}\text { Estou aberto a mudar minha forma de } \\
\text { pensar? }\end{array}$ & $\begin{array}{l}\text { Reuniòes / Trabalho em } \\
\text { equipe }\end{array}$ \\
\hline \multirow{3}{*}{ Afabilidade } & Protagonismo & Gomes e Silva (2019) & \begin{tabular}{|l|} 
Sociabilidade / \\
Disposiçào para \\
mudanças / Liderança \\
\end{tabular} & $\begin{array}{l}\text { Você tem autonomia e consciência para } \\
\text { enfrentar problemas da sociedade? }\end{array}$ & Todas \\
\hline & Afetividade & Nakao et al. (2012) & Afetividade & $\begin{array}{l}\text { Você tem sensibilidade em relaçào aos } \\
\text { problemas enfrentados por outras } \\
\text { pessoas? }\end{array}$ & $\begin{array}{l}\text { Reuniòes / Trabalho em } \\
\text { equipe }\end{array}$ \\
\hline & Sociabilidade & Nakao et al. (2012) & Sociabilidade & $\begin{array}{l}\text { Você conseguiu ampliar sua rede de } \\
\text { relacionamentos? }\end{array}$ & Aulas / Trabalho em equipe \\
\hline \multirow{2}{*}{ Desempenho } & Detalhismo & Nakao et al. (2012) & Detalhismo & $\begin{array}{l}\text { Você conseguiu descentralizar as tarefas } \\
\text { e fazê-las da melhor forma possível? }\end{array}$ & Trabalho em equipe \\
\hline & Tempo de Execução & Nakao et al. (2012) & Tempo de Execuçào & $\begin{array}{l}\text { Executou a tarefa durante o tempo } \\
\text { estipulado? }\end{array}$ & Trabalho em equipe \\
\hline
\end{tabular}

Fonte: elaborado pelos autores. 


\section{DADOS BIOGRÁFICOS DOS AUTORES}
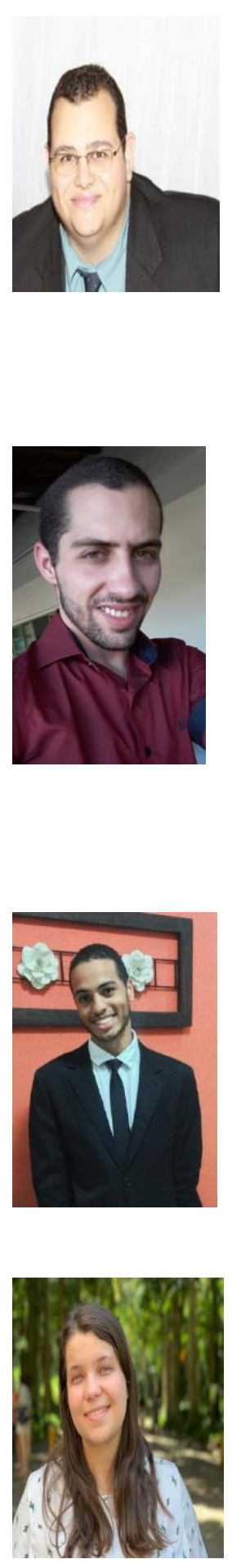

Wagner Ragi Curi Filho - Doutor em Administração de Empresas pela Escola de Administração de São Paulo da Fundação Getulio Vargas (2015-2018). Mestre em Engenharia de Produção pela Universidade Federal de Minas Gerais (2007-2009). Possui graduação em Engenharia de Produção pela Universidade Federal de Minas Gerais (2001-2006). Atualmente é professor Adjunto no Departamento de Engenharia de Produção do Instituto de Ciências Exatas e Aplicadas da Universidade Federal de Ouro Preto (DEENP/ICEA/UFOP). Desde março de 2019, é coordenador do curso de graduação em Engenharia de Produção e Coordenador do Centro de Extensão e Cultura de João Monlevade. Tem experiência em índices de desempenho, competências, organização do trabalho, economia solidária e avaliação de impacto de universidade na comunidade.

Paganini Barcellos de Oliveira - Doutor em Engenharia de Produção pela Universidade Federal de Minas Gerais (2015-2020). Mestre em Engenharia de Produção pela Universidade Federal de Minas Gerais (2013-2014). Possui graduação em Engenharia de Produção pela Universidade Federal de Ouro Preto (2008-2012). Atualmente é professor Adjunto no Departamento de Engenharia de Produção do Instituto de Ciências Exatas e Aplicadas da Universidade Federal de Ouro Preto (DEENP/ICEA/UFOP). Tem experiência em pesquisa e implementação de algoritmos exatos e heurísticos para problemas de localização e transportes em redes. As principais áreas de Interesse são: Pesquisa Operacional, Otimização de Sistemas Logísticos de Grande Porte, Microeconomia, Teoria dos jogos e Educação em Engenharia de Produção.

Bruno Souza Ramos - Graduando em Engenharia da Computação pela Universidade Federal de Ouro Preto (2015-Atual). Possui ensino técnico em Automação Industrial pelo CEFET - Ouro Preto (2011-2013). Tem experiência em desenvolvimento WEB e Mobile, voltado a soluções de negócios. As principais áreas de interesse são: UX/UI, Desenvolvimento Full Stack, e AI de análises comportamentais.

Isabella Maria Candido - Graduanda em Sistemas de Informação pela Universidade Federal de Ouro Preto (2018-Atual). Tem experiência com Gestão de Pessoas e Marketing, pela Visão Tecnologia e Sistemas - Empresa Júnior UFOP João Monlevade. Tem interesse voltado para solução de problemas através de tecnologias, gerenciamento de pessoas e projetos, com metodologias ágeis como o Scrum. 


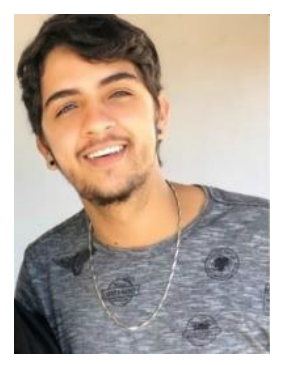

Vinicius Fernandes Silva - Graduando em Engenharia de Produção pela Universidade Federal de Ouro Preto (2017-Atual). Possui ensino Técnico em Eletroeletrônica e Aprendizagem em Elétrica Predial, ambos pelo SENAI-Itabira. Tem experiência em Marketing pela Ascender Jr - Empresa Júnior UFOP. Foi Assessor da Coordenadoria Financeira do CreaJr - MG e atualmente é Coordenador Adjunto da mesma coordenadoria. 